the puddling furnace, as cast-iron becomes converted by oxidation into puddled iron, may, perhaps, be considered similar to that which occurs in the reduction of silver sulphide by hydrogen.

The complete removal of impurities from the iron requires a temperature approaching fusion, and the fibers resulting as the metal becomes nearly pure are united into a mass.

\title{
THE PROTEIDS OF THE KIDNEY BEAN.
}

(Phaseolus Vulgaris.)

BY Thomas B. OSBORNE.

(Continued from page 643.)

Another portion of the bean-meal was extracted with a considerable quantity of one per cent. sodium chloride solution; the extract was filtered as clear as possible, and dialyzed in a large vessel containing alcohol. The globulin readily separated after a short time, in well-formed tetrahedral crystals mixed with amorphous matter. This precipitate was filtered off, treated for forty-eight hours with one per cent. sodium chloride solution, filtered clear and again precipitated by dialysis in alcohol, at first quite dilute, but afterwards of gradually increased strength. The substance now separated in large well-formed tetrahedral crystals, the edges of which were slightly curved. This precipitate was filtered off, washed with water, alcohol, and ether, dried and analyzed with results as follows:

\begin{tabular}{|c|c|c|c|c|}
\hline \multicolumn{3}{|c|}{ Phaseolin, Preparation is } & \multicolumn{2}{|c|}{ CRYSTAIS. } \\
\hline & I. & II. & Average. & Ash-free. \\
\hline Carbon.......... & 50.98 & ... & 50.98 & 52.70 \\
\hline Fydrogen ...... & 6.56 & $\ldots$ & 6.56 & 6.78 \\
\hline Nitrogen...... & $16.2 I$ & 16.10 & 16.16 & 16.71 \\
\hline Sulphur....... & 0.33 & 0.29 & 0.31 & 0.32 \\
\hline Oxygen ........ & $\ldots$ & $\ldots$ & $\ldots$ & 23.49 \\
\hline Ash $\ldots \ldots \ldots \ldots$ & 3.27 & $\cdots$ & 3.27 & .... \\
\hline
\end{tabular}

As dilute acids precipitate proteid substance when added to the sodium chloride extracts of the ground beans, it was thought desirable to make some preparations by this method. Accordingly an extract was prepared by treating the meal with one per cent. sodium chloride solution, and after clearing as completely 
as possible by subsidence and decantation, two-tenths per cent. hydrochloric acid was added until a considerable precipitate resulted. After standing some hours the precipitate was filtered off, dissolved in very dilute brine, filtered clear and precipitated by dilution. Only a small part of the substance separated. This preparation, I9, was then washed with water, alcohol and ether, dried and found to contain ash-free, I6.7 I per cent. of nitrogen.

The filtrate from 19 , when greatly diluted, gave a further precipitate, which, when filtered off and washed with water, alcohol and ether had the following composition:

Phaseolis, Preparation 20.

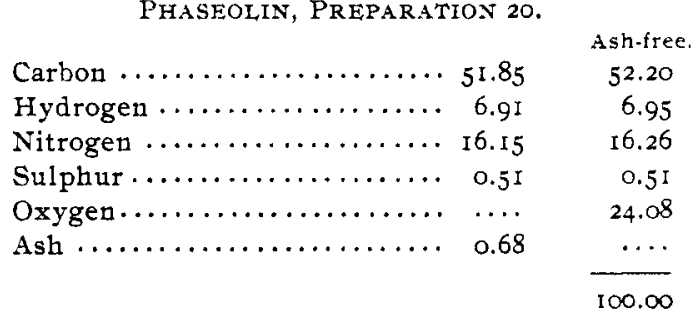

It is evident that the same globulin was obtained by this method as by those previously followed. Next to be noticed are two preparations of phaseolin, made by diluting the sodium chloride extracts in the manner already described, redissolving the precipitates first obtained in salt solution, and again precipitating by dilution. Preparation 2I, contained ash-free I6.65 per cent. of nitrogen.

Phaseolin, Preparation 22.

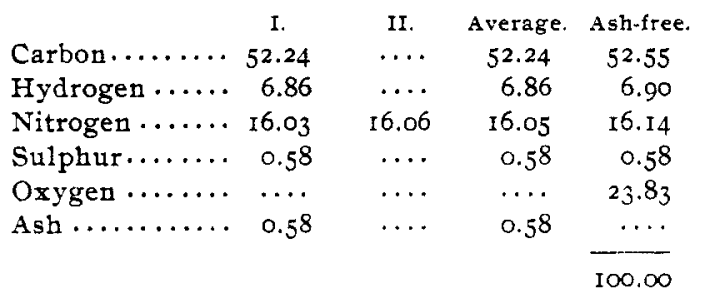

The filtrate from 22 was then treated with two-tenths per cent. hydrochloric acid, until a considerable precipitate resulted. This was filtered off, washed with water, alcohol and ether, and analyzed with the following results: 
Phaseolin, Preparation 23.

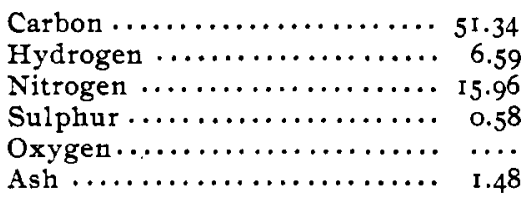

$$
\begin{gathered}
\text { Ash-free. } \\
52.12 \\
6.70 \\
16.21 \\
0.59 \\
24.38 \\
\cdots \cdots \\
\hline 100.00
\end{gathered}
$$

One more preparation of this globulin was made with special reference to its purity. For this purpose a considerable quantity of the globulin was precipitated from a one per cent sodium chloride extract of the beans, and after filtering off, was twice dissolved in dilute sodium chloride solution and precipitated by dilution after filtering clear. The final precipitate was thor-

\begin{tabular}{|c|c|c|c|c|}
\hline & I. & II. & Average. & Ash-free \\
\hline Carbon.......... & 52.45 & $52.5^{2}$ & 52.49 & $52 \cdot 75$ \\
\hline Hydrogen ...... & 6.99 & 6.80 & 6.90 & 6.95 \\
\hline Nitrogen ...... & I6.52 & 16.39 & 16.46 & 16.57 \\
\hline Sulphur....... & 0.56 & 0.44 & 0.50 & 0.50 \\
\hline Oxygen ........ & $\cdots$ & $\cdots$ & $\cdots$ & 23.23 \\
\hline Ash $\ldots . . . \ldots \ldots$ & 0.69 & $\cdots \cdot$ & 0.69 & $\cdots$ \\
\hline
\end{tabular}
oughly washed with water, alcohol and ether and analyzed. When dried over sulphuric acid, the preparation was readily soluble in dilute sodium chloride solution, and consisted entirely of the unaltered phaseolin. Its composition is shown by the analysis of preparation 24.

Phaseolin, Preparation 24.

The properties of phaseolin as shown by careful examination of preparation 24, dried over sulphuric acid, are as follows:

In cold or warm distilled water it is entirely insoluble.

In sodium chloride solution, and in very dilute acids and alkalies, it is very readily soluble to a clear solution.

Dissolved in ten per cent. sodium chloride solution, it is not precipitated by acetic, hydrochloric, nitric, or sulphuric acids, added in either minute or considerable quantities, although when dilute hydrochloric acid is added to the one per cent. sodium chloride extract of the beans, the phaseolin is precipitated.

Dissolved in large proportion in ten per cent. sodium chloride solution, the proteid is precipitated by adding much pure water. 
Solutions of phaseolin in brine are completely precipitated by saturation with ammonium sulphate, but only slightly by saturation with magnesium sulphate or sodium chloride.

Potassium terrocyanide and acetic acid together, give a precipitate.

With copper sulphate and caustic potash, the usual violet coloration is obtained, and with nitric acid, the xanthoproteic reaction.

Dissolved in ten per cent. sodium chloride solution and heated very slowly in a double water-bath, no turbidity occurs until the temperature is raised to $95^{\circ}$. This turbidity slowly increases as the temperature approaches $100^{\circ}$ and after some time, a flocculent precipitate begins to develop, which even after heating for an hour is but slight.

Like other plant-globulins, phaseolin separates from warm concentrated solutions on cooling, and from salt solutions on dialysis, in the form of spheroids.

The striking resemblance in composition of this proteid to the "myosins" found in the seeds of maize and oats, and also to animal myosin, is shown in the following table:

\begin{tabular}{|c|c|c|c|c|}
\hline & thaseolin. & $\begin{array}{c}\text { Maize } \\
\text { myosin. }\end{array}$ & $\begin{array}{c}\text { Oat } \\
\text { myosits.2 }\end{array}$ & $\begin{array}{l}\text { Animal } \\
\text { myosin } 8\end{array}$ \\
\hline Carbon......... & $5^{2} \cdot 5^{8}$ & 52.68 & 52.34 & 52.82 \\
\hline Hydrogen ..... & . $\quad 6.84$ & 7.02 & 7.21 & 7.11 \\
\hline Nitrogen ...... & - 16.48 & 16.82 & I 6.88 & I6.77 \\
\hline Sulphur....... & - 0.56 & 1.30 & 0.88 & 1.27 \\
\hline Oxygen $\ldots \ldots$ & - 23.54 & 22.18 & 22.69 & 21.93 \\
\hline & & $\infty . \infty 0$ & 100.00 & 0 \\
\hline
\end{tabular}

The four proteids, although having many properties in common, as well as a similar composition, are yet characterized by differences so considerable, as to leave no doubt of the individuality of each.

The maize myosin and animal myosin differ from the other two, by their greater content of sulphur, and also in coagulating, the former at $70^{\circ}$ and the latter at $55^{\circ} \mathrm{C}$.

Phaseolin presents many points of difference from the oat myosin. It is not precipitated from solutions in ten per cent.

1 Am. Chem. J., 13, 536.

2 Report Connecticut Agricultural Experiment Station for $1890,537-160 ;$ also $A m$. Chen. J., 13, 389; also Report Connecticut Agricultural Experiment Station for $7 \delta g 1,135$.

8 Studies from Laboratory of Physiological Chemistry, Yale University, 3, 133 
sodium chloride by acids, and but slightly by saturation with sodium chloride, and is thrown down, both by dilution and by dialysis, with much greater difficulty than the oat myosin.

Summary of ANalysis of Phaseolin from the Kidney Bean.

\begin{tabular}{|c|c|c|c|c|c|c|c|c|c|}
\hline$a-t$ & 1. & 2. & 52.60 & 4. & 5. & 6. & $\begin{array}{l}7 . \\
\ldots .\end{array}$ & $\begin{array}{l}8 . \\
52.72\end{array}$ & $\begin{array}{c}9 . \\
52.35\end{array}$ \\
\hline Hydrogen... & $\begin{array}{r}52.23 \\
6.95\end{array}$ & 6.69 & 6.72 & $\ldots$ & $\begin{array}{r}52.54 \\
6.83\end{array}$ & $\cdots$ & $\ldots$ & $7.24^{1}$ & 6.89 \\
\hline Nitrogen.... & 16.37 & I6.56 & I6.17 & 16.12 & $I 6.48$ & 16.23 & 16.87 & 16.45 & 16.52 \\
\hline Sulphur .... & 0.62 & 0.63 & 0.63 & $\ldots$ & $0.5^{8}$ & $\ldots \ldots$ & $\ldots$ & 0.67 & \\
\hline \multirow[t]{3}{*}{ Oxygen..... } & 23.83 & 23.52 & 23.88 & $\ldots$ & 23.57 & $\ldots$ & $\cdots$ & 22.92 & 24. \\
\hline & $1 \infty 0 . \infty$ & 100.00 & 100.00 & & 100.00 & & & 100.00 & 100.00 \\
\hline & Io. & II. & 12. & 13. & 14. & 15. & I6. & 17. & 18.2 \\
\hline Carbon...... & 52.74 & 52.49 & $\ldots$ & 53.06 & 52.49 & 52.47 & 53.22 & $\ldots$ & 52.70 \\
\hline Hydrogen... & 6.84 & 6.80 & $\ldots$ & 6.85 & 6.73 & 6.90 & 6.86 & $\cdots$ & $6.7^{8}$ \\
\hline Nitrogen.... & I6.65 & I 6.85 & I 6.67 & 16.68 & I6.45 & $16.00^{1}$ & I 6.48 & I6.29 & $16.7 \mathrm{I}$ \\
\hline \multirow{4}{*}{$\begin{array}{l}\text { Sulphur .... } \\
\text { Oxygen .... }\end{array}$} & 0.64 & 23.86 & $\ldots$ & $23.4 I$ & 24.13 & & $\left\{\begin{array}{l}0.48 \\
\text { f }\end{array}\right.$ & $\cdots$ & 0.32 \\
\hline & 23.13 & & & & & 24.05 & 22.96 & $\cdots$ & 23.49 \\
\hline & 100.00 & 100.00 & & 100.00 & 100.00 & 100.00 & 100.00 & & $100 . \infty$ \\
\hline & Ig. & 20. & 21. & 22. & 23. & 24. & Average. & \multicolumn{2}{|c|}{ Ritthausen. } \\
\hline Carbon...... & $\cdots$ & 52.20 & $\cdots$ & 52.55 & 52.12 & 52.75 & $5^{2 .} \cdot 5^{8}$ & \multicolumn{2}{|c|}{52.55} \\
\hline Hydrogen... & ... & 6.95 & $\ldots$ & 6.90 & 6.70 & 6.95 & 6.84 & \multicolumn{2}{|c|}{7.09} \\
\hline Nitrogen... & 16.71 & I6.26 & 16.65 & 16.14 & 16.21 & 16.57 & I6.48 & \multicolumn{2}{|c|}{ I6.18 } \\
\hline Sulphur .... & . $\ldots$ & 0.51 & ... & $0.5^{8}$ & 0.59 & $0.5^{\circ}$ & 0.56 & \multicolumn{2}{|c|}{0.43} \\
\hline Oxygen.... & $\ldots$ & 24.08 & $\cdots$ & 23.83 & $24 \cdot 3^{8}$ & 23.23 & 23.54 & \multicolumn{2}{|c|}{23.75} \\
\hline & & & & & & & & \multicolumn{2}{|c|}{$100 . \infty$} \\
\hline
\end{tabular}

Preparation of Phaselin.

Proteid Remaining in Solution after Separation of the Globulin Just Described.

After precipitating phaseolin by the various methods employed in making the foregoing preparations, the extracts contained proteid matter which could be separated by dialysis in distilled water, by adding acids and by prolonged heating.

These methods of precipitation gave products of nearly uniform composition, except in those cases where the phaseolin had been incompletely separated. Preparations of phaselin were accordingly made as follows :

When a portion of the dialyzed solution from which preparation I had been separated, was heated slowly it became turbid

1 Omitted in making ave rage.

2 Tetrahedral crystals. 
at $40^{\circ}$, flocks appearing at $68^{\circ}$ in considerable quantity. When filtered, after heating at $72^{\circ}$, a second turbidity was obtained at $83^{\circ}$, and flocks formed at $87^{\circ}$ in greater quantity than at $68^{\circ}$. The remaining solution was dialyzed in alcohol until its volume was reduced by one-half. An equal bulk of strong alcohol was then added to the contents of the dialyzer, and the mixture allowed to stand until the precipitate settled. After three days the solution was decanted and the precipitate washed with absolute alcohol and ether and dried over sulphuric acid. The substance, thus dried, weighed eleven grams. It was finely ground, thoroughly extracted with distilled water, and this extract filtered from the large insoluble residue. The clear solution was then found to become turbid when heated to $63^{\circ}$ and to yield a flocculent coagulum at $76^{\circ}$. The entire solution was therefore heated for several hours in a water-bath at $80^{\circ}$, and the coagulum filtered off, washed thoroughly with water, alcohol and ether and dried over sulphuric acid. The 0.9 gram of substance thus obtained, was dried at 1 Io and analyzed with the following result. Preparation 25.

Phaselis, Preparation 25.

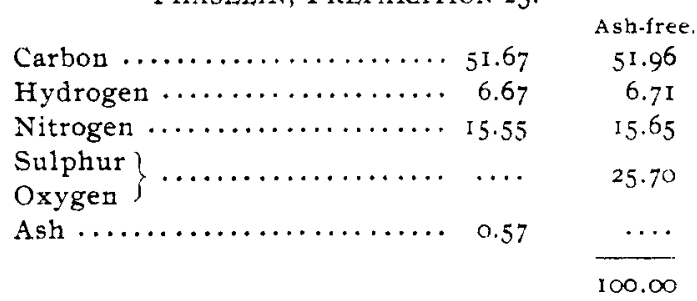

When the filtrate from 25 was again heated to $80^{\circ}$, a further coagulum resulted. The solution was accordingly kept at this temperature as long as any coagulum was produced, filtered, and the coagulum washed with hot water, alcohol, and ether, and dried for analysis at $110^{\circ}$. This preparation, 26 , contained, ash-free, 14.57 per cent. of nitrogen and weighed 0.71 grain.

Two other preparations were made from the filtrate from preparation 3 , in nearly the same way as the two last described, the only difference being that the solution was precipitated with alcohol without first concentrating by dialysis in alcohol.

The first coagulum, preparation 27 , obtained by heating at 
$80^{\circ}$, weighed only 0.17 gram, and when dry contained without correction for ash, 14.90 per cent. of nitrogen. The second weighed one gram and had the following composition:

Phaselin, Preparation 28.

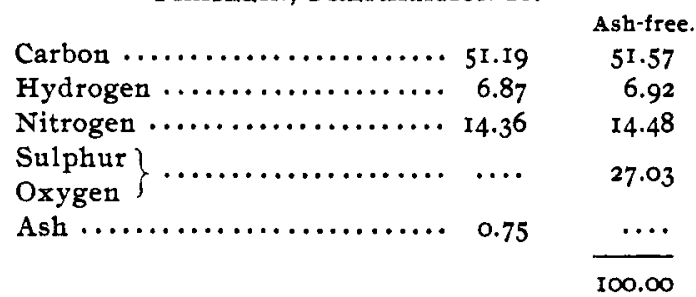

After largely diluting, the filtrate from preparation 16 failed to give any further precipitate on passing carbon dioxide through it for some time. The greater part of this solution was then thrown away, but by chance a little acetic acid was added to the remainder and found to produce a precipitate. This precipitate was filtered off, washed with water, alcohol, and ether, and when dried, weighed 0.27 gram and contained without correction for ash, I4.8I per cent. of nitrogen. Preparation 29.

Another preparation was then made by extracting bean meal with one per cent. brine, diluting the extract with a large quantity of water, and filtering off the precipitate. The filtrate was then treated with two-tenths per cent. hydrochloric acid until a considerable precipitate resulted, which was filtered off and the solution again treated with two-tenths per cent. hydrochloric acid. This final precipitate was filtered off, washed with alcohol and ether and gave one gram of preparation 30 , having the following composition:

Phaseinin, Preparation 30.

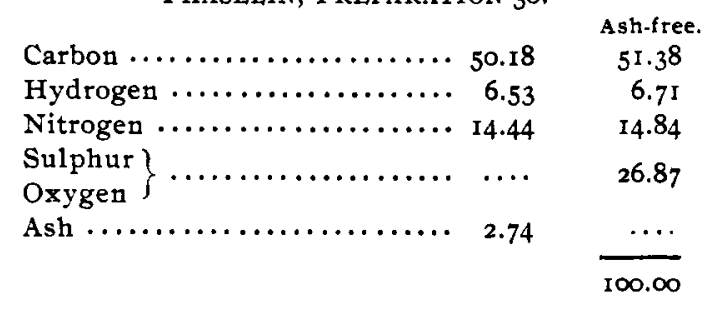

Again, the filtrate from preparation Io, was treated with an equal volume of strong alcohol and allowed to stand over night. 
The next morning, the precipitate which had separated was filtered off and treated with water. This dissolved some of the substance. This solution, filtered clear, when heated, gave a flocculent coagulum at $80^{\circ}$. With acetic, hydrochloric, or nitric acid, it gave a precipitate when the reagents were added in sufficient quantity. These precipitates were soluble in sodium chloride solution, and those produced by hydrochloric and nitric acids, were soluble in an excess of the acid, but that given by acetic acid, was not noticeably soluble in an excess. The precipitate obtained with nitric acid, did not dissolve upon warming, as is the case with such precipitates yielded by proteoses. The reaction of the extract was slightly acid, but it was not possible to precipitate anything therefrom, by the most careful neutralization. The whole solution was then treated with two-tenths per cent. hydrochloric acid; the precipitate thus formed had the following composition :

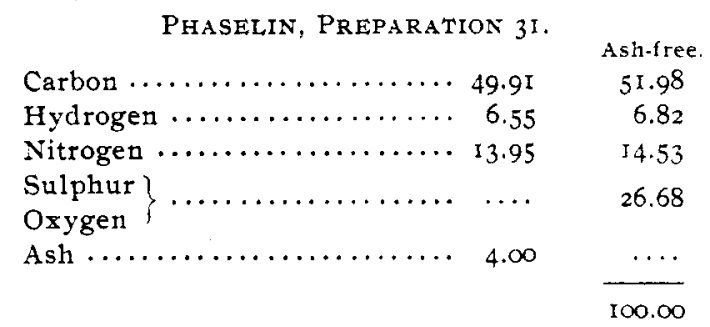

The precipitate from which 3 I was derived, after this extraction with water, was but slightly soluble in sodium chloride solution, and was therefore treated with two-tenths per cent. potash water. The resulting solution was filtered clear, and hydrochloric acid cautiously added, until a precipitate formed which was collected on a filter and treated in the usual manner. When dry, this preparation, 32 , weighed 3.3 grams.

The filtrate from 32 was further treated with two-tenths per cent. hydrochloric acid, and a second precipitate obtained which weighed 0.6 gram; preparation 33 .

Phasein, Preparation 32.

\begin{tabular}{|c|c|c|c|c|}
\hline & I. & II. & Average. & Ash-free \\
\hline$\cdots \cdots$ & 51.74 & $5^{I} \cdot 74$ & $5 \mathrm{I} \cdot 74$ & 52.65 \\
\hline en $\ldots .$. & 7.04 & 7.00 & 7.02 & $7 \cdot 14$ \\
\hline$n \ldots . .$. & 14.89 & $\cdots$ & 14.89 & 15.15 \\
\hline
\end{tabular}




\begin{tabular}{|c|c|c|c|c|}
\hline Sulphur $\}. . .$. & $\ldots$ & $\begin{array}{l}\text { II. } \\
\ldots \text {. }\end{array}$ & $\begin{array}{c}\text { Average. } \\
\ldots .\end{array}$ & $\begin{array}{c}\text { Ash-free } \\
25.06\end{array}$ \\
\hline Ash $\ldots \ldots \ldots \ldots$ & I. 78 & $\ldots$ & 1.78 & $\ldots$ \\
\hline
\end{tabular}

Phaseitin, Preparation 33.

Nitrogen $\ldots \ldots \ldots \ldots \ldots \ldots \ldots$ I4.24

Ash $\ldots \ldots \ldots \ldots \ldots \ldots \ldots \ldots, 4.12$

Ash-free.

I4.85

…

Another preparation was made by extracting 100 grams of bean meal, with Ioo cc. of one per cent. sodium chloride solution, and washing the insoluble residue with $100 \mathrm{cc}$. of the same solution, applied in successive portions. The entire extract was then filtered nearly clear, and dialyzed in alcohol. The alcohol of the outer vessel was frequently renewed, and the process was continued until practically all the proteid matter had separated. The precipitate was then filtered off and extracted with one per cent. sodium chloride solution. Much of the substance remained undissolved. The solution was filtered clear and dialyzed again in alcohol of $0.85 \mathrm{sp}$. gr. which was renewed once during the process. The precipitate resulting was filtered off and washed with dilute alcohol, absolute alcohol and ether and dried at $\mathrm{I} \mathrm{ro}^{\circ}$. Its composition was as follows :

Phaseitin, Preparation 34.

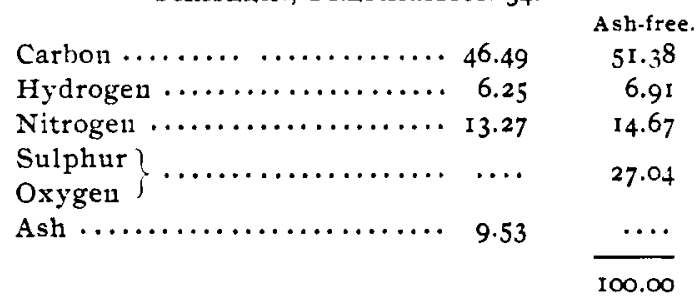

In order to obtain a purer preparation of the proteid by this method, 200 grams of bean meal, first extracted with petroleumbenzine, were treated with one liter of one per cent. sodium chloride solution and after squeezing out, the residue was mixed with another liter of the same solution and again squeezed. After standing over night, the turbid extract was decanted and dialyzed in alcohol for three days, the alcohol being once renewed. This treatment precipitated nearly all the proteids, which were 
collected on a filter, and after the solution had run off, the precipitate was suspended in one-quarter per cent. sodium chloride solution, filtered off and washed with the same solution. The clear filtrate and washings were then dialyzed into alcohol until a considerable precipitate had formed which was filtered off and washed successively with fifty per cent. alcohol, stronger alcoliol, absolute alcohol, and ether, and dried over sulphuric acid. It was then almost wholly soluble in water, but after drying at 110 " it became insoluble, and was washed with water, alcohol, and ether, and again dried, 35.

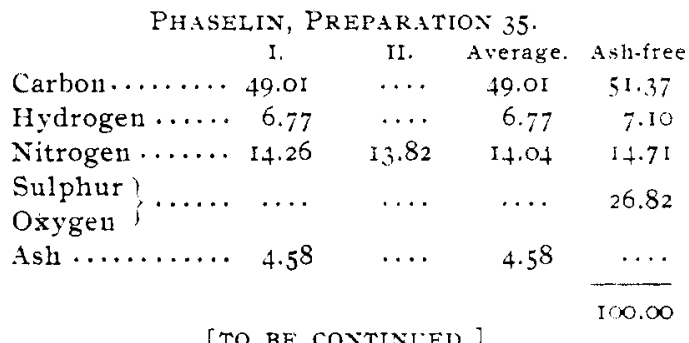

\section{THE DETERMINATION OF ALBUMEN IN COW'S MILK.}

Br I. L. VAN SLIKE

Recejed August 22, 1894.

IN Vol. 15, No. I of the Journal of THE AMEricas ChemICAL SocIETY, the writer presented a paper on the determination of casein in cow's milk. It is now desired to present another paper supplementary to that and relating to the determination of albumen in cow's milk.

Ordinarily, when we speak of milk albumen, we mean the portion of nitrogen compounds not coagulated by rennet, acid, etc. In other words, we apply the term albumen to the nitrogen compounds left after removing the casein proper. This use of the term albumen is inaccurate, because, after removing from normal milk its casein, there remain, at least, two nitrogen compounds or classes of nitrogen compounds. One of these is coagulated by heat, especially in the presence of dilute acids, while the other is not coagulated under these conditions. To the former only of these two, the term albumen is properly applicable. 